\title{
Formulation of Tablets Containing Mesoporous Silica Nanoparticles Loaded with Pramipexole
}

\author{
Christina Voycheva ${ }^{1, *}$, Teodora Popova ${ }^{1}$, Marta Slavkova $^{1}$, Diana Tzankova $^{2}$, Borislav Tzankov ${ }^{1}$ \\ ${ }^{1}$ Department Pharmaceutical Technology and Biopharmacy, Faculty of Pharmacy, Medical University of Sofia, Sofia, BULGARIA. \\ ${ }^{2}$ Department of Pharmaceutical Chemistry, Faculty of Pharmacy, Medical University of Sofia, Sofia, BULGARIA.
}

\begin{abstract}
Background: In order to develop final pharmaceutical product, the mesoporous silica particles loaded with pramipexole should be further formulated in the applicable solid dosage forms - tablets. The aim of the study was preparation of tablets containing MCM41 particles loaded with pramipexole. Materials and Methods: Mesoporous silica particles empty and loaded were subjected to dynamic light scattering analysis (DLS), transmission electron microscopy analysis (TEM) and infrared spectroscopy (IR). Modification of drug release was achieved by further formation of double chitosan/alginate coating. The formulation of tablets was made using diluents, a binder, disintegrate, glidant and a lubricant as well as the silica particles loaded with pramipexole. Flow ability and compressibility of the initial powder mixtures and were examined by tapping method calculating the Carr index and Hausner ratio. Direct compression method was used for tablet preparation. The crushing strength, friability of the tablets and their disintegration time were determined. In-vitro release profiles showed that tablet form influenced first stages of pramipexole release in both $\mathrm{pH}$ values, used in the study $(\mathrm{pH} 1.2$ and $\mathrm{pH}$ 6.8). Results: Final pharmaceutical dosage form tablets were successfully formulated with pramipexole loaded MCM-41. No change in mesopourous structure and other characterisic properties of used nanoparticles was observed. Improved profile in first release stage were observed. Conclusion: The use of polymers such as chitosan and sodium alginate in silica particles modification successfully delay the process of releasing pramipexole from MCM-41.
\end{abstract}

Key words: MCM-41, Pramipexole, Chitosan, Sodium alginate, Modified release.

\section{INTRODUCTION}

Since MCM-41 mesoporous silica materials were proposed as drug delivery carriers in 2001, ${ }^{1}$ these inorganic materials are currently widely used as drug carriers due to its favorable and tunable properties, thermal and mechanical stability, biocompatibility and possible modification of drug release..$^{2-9}$ Due to the small size of MCM-41 particles, they could easy interact with the cell membranes or penetrate inside the cells. The mesoporous structure of silica nanoparticles allows highly efficient loading of drugs and effective control of the release of active substance. In addition, mesoporous silica materials are often chosen due to its well- ordered structure and large surface area, which allows release and loading of drug molecules and allows their application in the pharmaceutical technology. MCM-41 based nanoparticles are widely developed as oral drug delivery systems for active ingredients with different physico-chemical properties. ${ }^{10,11}$ These systems have all the advantages of multiparticle drug delivery systems such as high specific surface and minimal risk of dose dumping. Along with a number of advantages, the use of multi-particular Nano sized MCM41 drug delivery systems possess some problems from pharmaceutical point of view, mainly related with the need of
Submission Date: 18-09-2020; Revision Date: 15-02-2021; Accepted Date: 07-06-2021

DOI: 10.5530/ijper.55.3.141 Correspondence: Dr. Christina Voycheva Department Pharmaceutical Technology and biopharmacy, Faculty of Pharmacy, Medical University of Sofia, Sofia 1000, BULGARIA.

Phone: +359-888-367762 Email id: hrisky@gmail.com

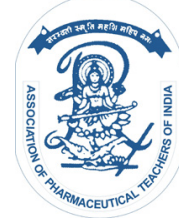

www.ijper.org 
elaboration of suitable dosage form, especially when oral administration is expected. In this case solid dosage forms like tablets are preferred due to simple and wellknown preparation process and high stability. It is widely known that particle size is a critical parameter in tablets formulation which is directly connected with powder flow ability and proper dosing of the active ingredients. Along with the worse flow ability, some researchers reported that micro and nanoparticles size is in a direct relationship with tensile strength, so larger particles appear to have better binding between particles. ${ }^{12}$ There are some researches regarding the size effect of micro particles on compaction and tablet formation. ${ }^{13,14}$ It was observed that yield stress generally increases with particles size decrease. However, there are only a few reports demonstrated successful preparation of solid dosage forms containing mesoporous silica particles. ${ }^{15}$

Pramipexole is a third generation full agonist of dopamine receptor with a non-ergot structure. It is used successfully in the treatment of Parkinson's Disease (PD). The dopamine agonists have a effect directlly the dopamine receptors. Different typs of them have varition of their half-life and acting on different subtypes dopamine receptors. The latest, third generation, dopamine agonists have long halflife, and shows prolonged postsynaptic activation of dopamine receptors. ${ }^{16}$ Parkinson's patients, even those using the latest generation of dopamine agonists, have reported dose-dependent side effects that require special care. The central and peripheral nervous systems are most commonly affected, with psychiatric, nervous, cardiovascular, and gastrointestinal reactions ${ }^{17}$ It is well known that the frequency of the side effects could be minimized by elaboration of modified-release dosage forms and reducing of dose by dose individualization. Pramipexole has very good water solubility and it is a factor which limits incorporation of drug in sustainedrelease formulations. ${ }^{18}$ But surface modified MCM-41 particles seem to be effective carrier for pramipexole delivery, because of suspected incorporation of drug into their pores. Multi-particular nanosized composition helps to individualizing the dose of pramipexole, which is desirable possibility for reducing of side effects. High mechanical stability of MCM-41 allows incorporation of the particles in solid dosage forms such as tablets. Opportunity for further sustain the release of the easily soluble pramipexole is further covering of the loaded silica nanoparticles with suitable polymers. Their swelling in an aqueous environment would allow even without the inevitable release burst effect.
Chitosan is N-deacetylated derivative of chitin, wich is non-toxic, biocompatible and biodegradable linear copolymer. Because of non-completed $\mathrm{N}$-deacetylation has many exposed amino groups that making it polycationic polysaccharide. ${ }^{19}$ Protonation of amino groups allow to chitosan to form electrostatic complexes with other negatively charged molecules. ${ }^{20}$

Sodium alginate is a polysaccharide from natural origin. It is constituent of guluronic and mannuronic acid monomers and their ratio and order vary through the polymer chain. ${ }^{21}$ From chemical point of view, alginates are linear unbranched polysaccharides with anionic charge and hydroxylic and undissociated carboxylic groups can be found within their structure. ${ }^{22}$ The excellent biocompatibility and biodegradability of alginate make it very widely used for biomedical application and especially for drug delivery systems. ${ }^{23}$

The aim of the study was preparation of solid dosage forms (tablets) containing double polymer coated MCM-41 particles loaded with pramipexole. Positively charged chitosan and negatively charged sodium alginate were chosen for suitable agent for polymer coating.

\section{MATERIALS AND METHODS}

Mesoporous silica MCM-41 type (hexagonal) with determined characteristics (average particle size 400 $\mathrm{nm}$, pore size $2.6 \mathrm{~nm}$, surface area $1003 \mathrm{~m}^{2} / \mathrm{g}$ and free volume $1.07 \mathrm{~cm}^{3} / \mathrm{g}$ ) was purchased from Sigma-Aldrich (St. Louis, USA). Avicel PH102, hydroxymethylcellulose, lactose, starch, magnesium stearate and PEG 6000 were purchased from BASF (Germany). Colloidal silica dioxide was purchased from Evonik (Germany). Sodium hydrogen phosphate was purchased from Sigma Aldrich (St. Louis, USA). Deionized water was prepared by ion exchange.

\section{Loading of pramipexole into MCM-41 silica mesoporous particles}

Loading of pramipexole on mesoporous silica particles was perform in water at $37^{\circ} \mathrm{C}$ applying pramipexole and MCM-41 in ratio 1:1 by using solvent impregnation method. Afterincubation ( $24 \mathrm{~h}$ ), the waterwas evaporated under vacuum and particles under vacuum were dried for $12 \mathrm{~h}$ at $25^{\circ} \mathrm{C}$ temperature. Ethanol $95 \%$ was used for washing the dried particles. Finally, dispertion with loaded particles was filtered under vacuum through a membrane filter with pore size $0.1 \mu \mathrm{m}$. The rest of the solvent was dried for $24 \mathrm{~h}$ at $25^{\circ} \mathrm{C}$ under vacuum.

\section{Coating of loaded mesoporous particles}

The covering of the drug-loaded particles was achieved by following soak and stirring for $1 \mathrm{~h}$ in $0.12 \%$ aqueous 
solutions of alginate and chitosan. After each soaking with different polymer (chitosan and sodium alginate), the heterogenic system was centrifuged at $17000 \mathrm{rpm}$ for $20 \mathrm{~min}$, rinsed with distilled water, redisposed at vortex shaker and separated by second centrifugation. The resulted double coated pramipexole loaded MCM41 were finally dried for $12 \mathrm{~h}$ at $25^{\circ} \mathrm{C}$. The sample were abbreviated as MCM-41/Prami (non-coated) and MCM41/Prami/Chit/Alg.

\section{Loading capacity}

Pramipexole loading was calculated by determination of the amount in the supernatant of non- entrapped drug in silica particles after soaking in drug solution or polymer covering procedure. Spectrophotometer was used to detect the amount of pramipexole in the supernatant using the procedure, described in in-vitro release section.

\section{Pysicochemical characterization of initial, pramipexole-loaded and double-coated MCM-41 particles}

Particle's shape and preservation of the structures following drug loading and coating were identified using a electron transmission microscopy (TEM) (JEM-2100F $200 \mathrm{kV}$.r. $0.23 \mathrm{~nm})$.

Record of infrared spectroscopy (IR) spectra were made by spectroscopy apparatus Nicolette 400 over the spectral region 4000 to $400 \mathrm{~cm}^{-1}$.

Determinations of size, index of polydispersity and zeta potential were carry out using (Nano ZS zetasizer, UK Worcestershire,). The samples were added in purified water and measured at a scattering angle of $25^{\circ}$ and $90^{\circ}$. Triplicate measurements were made.

\section{Preparation and characterization of tablets}

Tablets with total weight $150 \mathrm{mg}$ containing $0.75 \mathrm{mg}$ pramipexole (pure or encapsulated) were prepared by direct compaction method using Avicel PH 102, HPMC, lactose, starch, colloidal silica dioxide, $\mathrm{Mg}$ stearate and PEG 6000. Single punch tablet press Erweka AR401 (Germany) equipped with $6 \mathrm{~mm}$ punches was used. The tablet's composition is presented in Table 1.

Flow ability and compressibility of the initial powder mixtures were examined by tapping method calculating the Carr index and Hausner ratio according to USP (ERWEKA type SVM20).

The crushing strength of the tablets was defined as the force $(\mathrm{N})$ needed to fracture the tablet completely (TBH 30 Erweka, Germany).

The friability of tablets was determined using a friabilator (PTF 20 DDFT, Federal German rep) after 100 rotation of drum according to Ph.Eur. The calculated weight loss in \% was signify as the friability of tablets.

Time for disintegration of tablets was detects according to European Pharmacopoeia with a disintegration tester (ZT ERWEKA 72, Federal German rep). In the six tubes basket of apparatus six tablets were placed. The basket was positioned in sufficient volume of disteled water at $37 \pm 2^{\circ} \mathrm{C}$. The complete disintegration time in minutes for the six tablets was measured.

\section{In-vitro release from nanoparticles and tablets}

Buffers with $\mathrm{pH}$ values 1.2 and 6.8 were used for dissolution tests. In vitro release research were conducted applying the United States Pharmacopeia Apparatus type 2 (paddle method) $-0.2 \mathrm{mg}$ nanoparticles loaded with Pramipexole, a tablet was dispersed in $900 \mathrm{ml}$ of the buffers. $5 \mathrm{ml}$ samples were taken at 5, 15, 30, 45, 60, 120, $180 \mathrm{~min}$. The samples were centrifuged at $15000 \mathrm{rpm}$ for $15 \mathrm{~min}$ and the released amount was identified on UV-vis spectrophotometer at $262 \mathrm{~nm}$, according to the standard curve ( $r>0.997)$.

\section{RESULTS AND DISCUSSION}

Drug loading and characterization of loaded with pramipexole MCM-41. The solvent impregnation method is considered as appropriate and efficient method for loading of active substance in mesoporous silica materials. ${ }^{10}$ In our study, the encapsulation efficiency reached $48 \%$ using solvent impregnation method (Figure 1). Efficient drug loading can be explained with mesoporous structure of the particles which possess high free volume. According to IUPAC classification the size of the pores is in mesoscale (2.6 $\mathrm{nm}$ ) which allows free entry of most drug molecules

Table 1: Composition of tablets containing pramipexole loaded nanoparticles (MCM-41/Prami-T) or non-encapsulated pramipexole (Prami-T).

\begin{tabular}{|c|c|c|}
\hline Compounds, $\mathbf{m g}$ & MCM-41/Prami-T & Prami-T \\
\hline MCM-41/ Prami & 0.197 & - \\
\hline Prami & - & 0.075 \\
\hline Avicel PH 102 & 40.0 & 40.0 \\
HPMC & 10.0 & 10.0 \\
Aerosil 200 & 5.0 & 5.0 \\
\hline Starch & 63.8 & 63.9 \\
\hline Lactose & 30.0 & 30.0 \\
\hline PEG 6000 & 0.5 & 0.5 \\
\hline Mg stearate & 0.5 & 0.5 \\
\hline TOTAL & 150.0 & 150.0 \\
\hline
\end{tabular}


inside the mesopores. Our preliminary studies showed that using of typical solvent impregnation method (in water) led to insufficient efficacy of pramipexole loading due to the high water solubility of the drug. We modified the method including an additional step - evaporation of water and washing of surface located unloaded pramipexole with ethanol. This change led to minimized losses of drug due to the lower ethanol solubility of pramipexole $(5 \mathrm{mg} / \mathrm{ml})$ compared to its water solubility. ${ }^{24}$ Aiming to achieve sustained drug delivery, the drug loaded particles were post-coated with polymers. In particular, double polymer coating using consequently chitosan and sodium alginate was performed. The loading capacity after post covering of the systems with chitosan and sodium alginate slightly decreased (Figure 1) probably due to a drug diffusion during the coating.

Physicochemical characterization of initial, pramipexole-loaded and double-coated MCM-41 particles was made by DLS method, TEM and FTIR measurements.

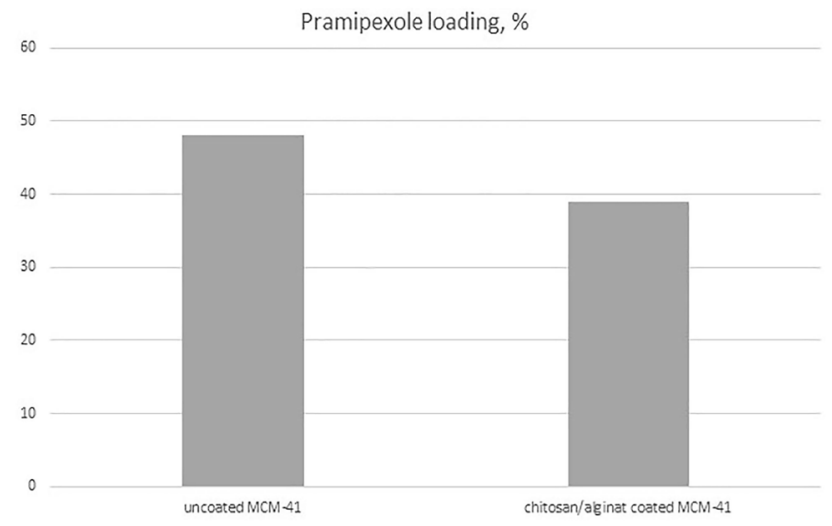

Figure 1: Encapsulation efficiency of uncoated and chitosan/ alginate coated MCM-41, loaded with pramipexole.

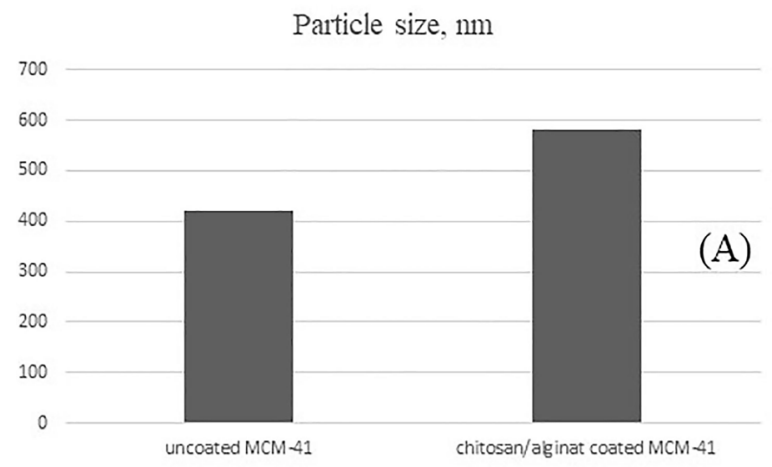

The size of uncoated pramipexole loaded particles was similar to the size of parent (empty) particles, 416 and $420 \mathrm{~nm}$ respectively (not shown). However, the size of the non-coated and coated MCM-41 particles was significant larger (Figure 2A), which was indication for successful polymer coating.

The index of polydispersity is presented on Figure 2B. Similarly, the polydispersity of the coated samples showed a tendency to increase. These results could be explained with changes of the surface properties of the coated particles and possible formation of aggregates during coating procedures. In general, DLS measurements were in good accordance with TEM measurements (Figure 3). In addition, the images showed spherical shape and preserved mesoporous structure of the loaded particles. Thus, the drug loading did not influence the mesoporous structure.

Zeta potential of initial (empty) particles MCM-41 show typical negative value $(-27 \pm 5 \mathrm{mV})$ which can be explained with surface located silanol groups. Incorporation of pramipexole led to change in the zeta potential from negative to slightly positive $(+13 \pm 3 \mathrm{mV})$. This difference probably is due to the amino groups of pramipexole and affirm successful loading of the drug into the channels. Double (chitosan/sodium alginate) polymer coating led to alteration of surface charge of the systems to strongly negative $(-45 \pm 8 \mathrm{mV})$. The result is caused by influence of sodium alginate on the zeta potential and proves successful polymer coating.

These facts were confirmed by FTIR measurements. IR spectra of MCM-41, pure pramipexole, sodium alginate, chitosan, and drug loaded MCM-41 and double coated drug loaded- nanoparticles are shown in Figure 4. The characteristic absorption peaks of pure drug were found at the wave numbers of $3409,2945,1585$, 1308 and $759 \mathrm{~cm}^{-1}$ responsible for functional groups of $\mathrm{N}-\mathrm{H}$ stretching, $\mathrm{C}-\mathrm{H}$ stretching, $\mathrm{C}=\mathrm{C}$ stretching, $\mathrm{C}-\mathrm{N}$

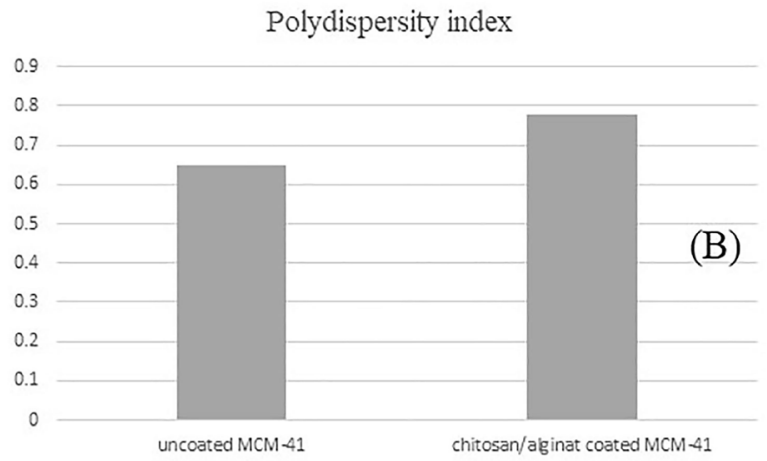

Figure 2: Size (A) and polydispersity index (B) of uncoated and chitosan/alginate-coated MCM-41 particles determined by DLS measurements. 

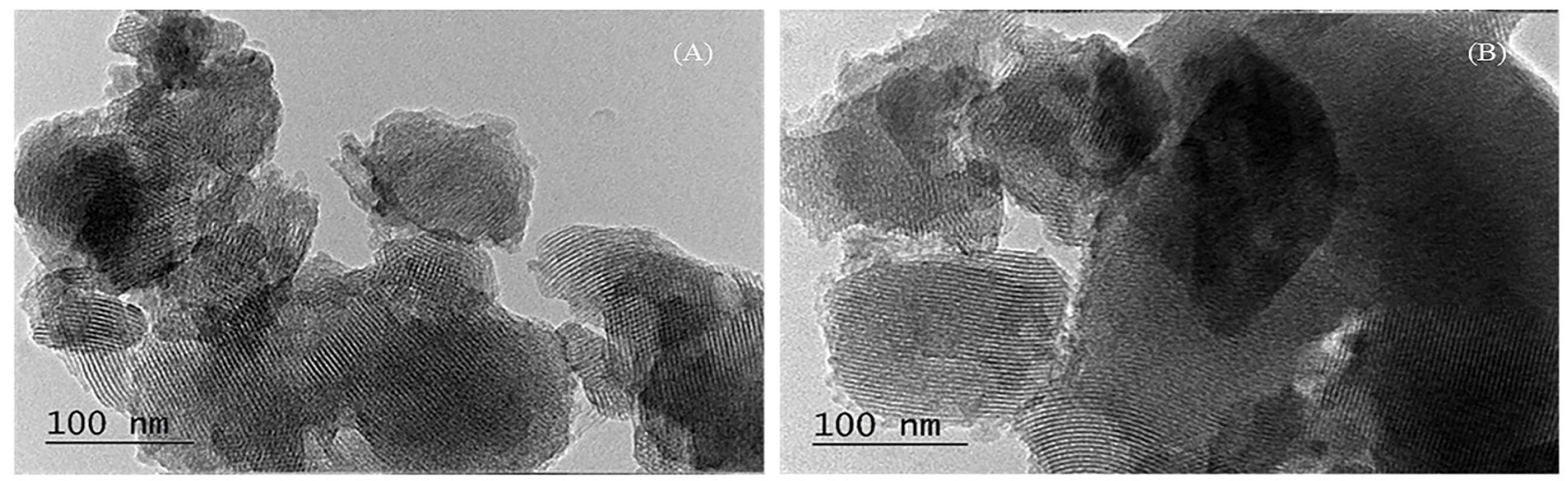

Figure 3: TEM of uncoated (A) and chitosan-alginate coated MCM-41, loaded with pramipexole (B).

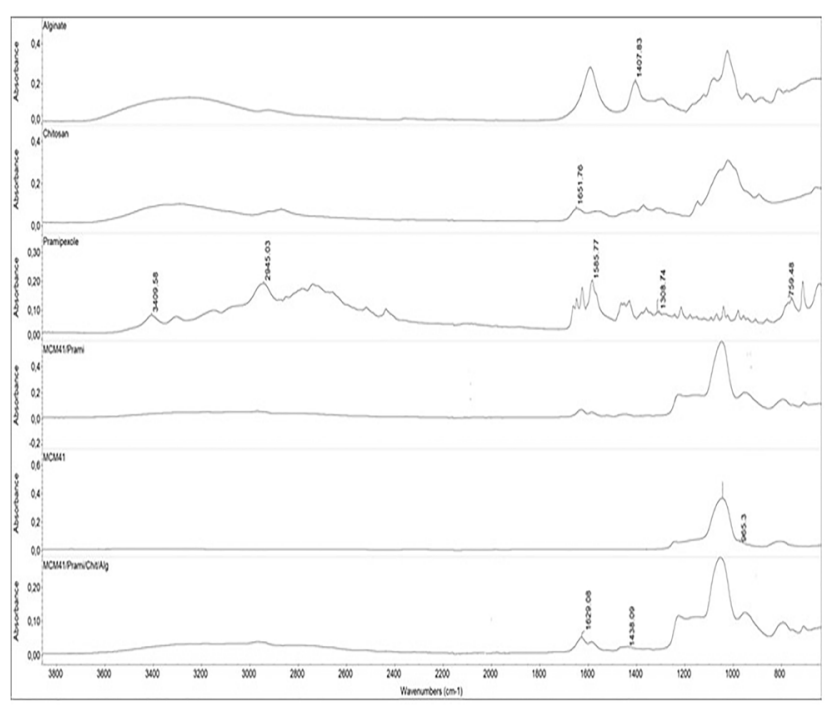

Figure 4: FTIR spectra of pure MCM-41, pramipexole-loaded (MCM-41/Prami) and polymer-coated particles (MCM-41/Prami/ Chit/Alg, compared to the spectra of pramipexole, chitosan and sodium alginate.

stretching and $\mathrm{C}-\mathrm{H}$ bending respectively. ${ }^{25}$ They were not found in the spectrum of Prami-MCM-41, most likely due to the successful loading of Prami into the pores of MSM-41. The FTIR spectra of MCM-41 was characterized by an intensive band at $1054 \mathrm{~cm}^{-1}$ which was due to the asymmetric stretching vibration of silica structure ( $\mathrm{Si}-\mathrm{O}-\mathrm{Si}$ ), also the band at $965 \mathrm{~cm}^{-1}$ was corresponding to the stretching vibrations of surface $\mathrm{Si}-\mathrm{O}$ groups. ${ }^{26,27}$ No shifting in the characteristic picks occurs after entrapment of pramipexole into the pores of MCM-41 particles, suggesting absence of interaction between silanol groups of MCM-41 and functional groups of pramipexole.

The absorption band in the IR spectra of chitosan at $1651 \mathrm{~cm}^{-1}$ corresponded to the $\mathrm{C}=\mathrm{O}$ stretching of the secondary amide presenting in the IR spectrum of sodium alginate the band at $1407 \mathrm{~cm}^{-1}$ is associated to symmetric stretching vibrations of carboxylate ion. ${ }^{28}$ Pramipexole loaded and double coated MCM-41 showed that stretching of -COO- groups shifted to $1438 \mathrm{~cm}^{-1} .^{29}$ The absorption band at $1651 \mathrm{~cm}^{-1}$ of chitosan shifts to $1629 \mathrm{~cm}^{-1}$ after electrostatic interaction with alginate. These results indicate that the carboxylic groups of alginate associate with the amino-groups of chitosan through ion interactions to form the polyelectrolyte complex.

Next step in our study was to evaluate the in vitro release process of uncoated and polymer coated samples. Dissolution tests were performed in $\mathrm{pH}$ buffers typical for GI tract $(\mathrm{pH}=1.2$ and $\mathrm{pH}=6.8)$ considering oral administration of the systems. The results showed similar profiles of pramipexole in both $\mathrm{pH}$ media. It was important that the initial burst release of pramipexole was lower when the particles were coated with the polymers. Thus, the coating was appropriate approach that reduces the undesired initial burst release.

As seen, the release profiles from uncoated and chitosan/ alginate-coated particles in different $\mathrm{pH}$ media showed significant differences in the dissolution rate (Figure 5). Polymer covering led to slower pramipexole release, compared with the non-covered particles, pramipexole was fully released within 5 min.

\section{Preparation of tablets}

Our study continued with preparation of tablets containing the pramipexole loaded MCM-41 nanoparticles. Compilation of tablets ingredients is presented on Table 1.

The first step before compaction was evaluation of flow ability and compressibility of tableting mixtures. Thus, tapped and bulk density were calculated by performance of tapping method in accordance with requirements of $\mathrm{Ph}$. Eur. The values of tapped and bulk density were 

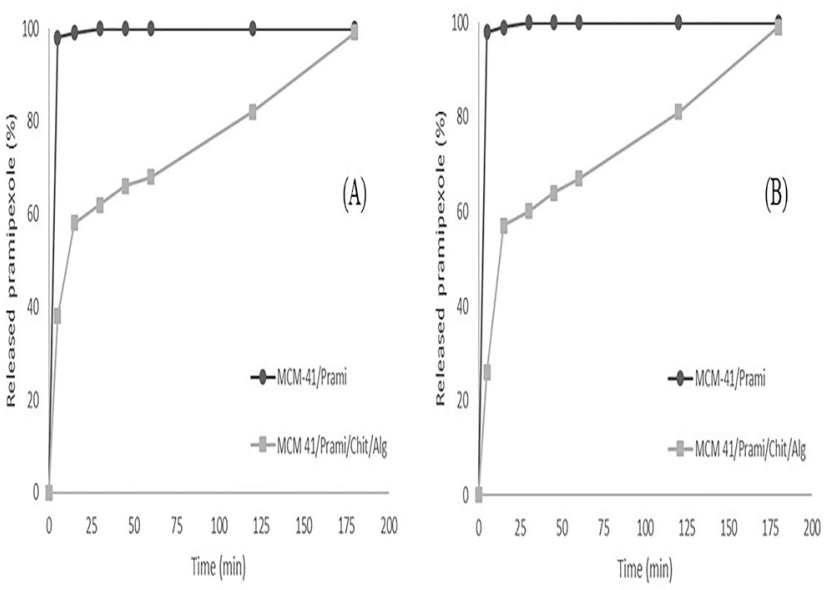

Figure 5: Release profiles of pramipexole from non-coated and chitosan/alginate-coated MCM-41 nanoparticles in pH 1.2 (A) and pH $6.8(B)$.

Hausner ratio

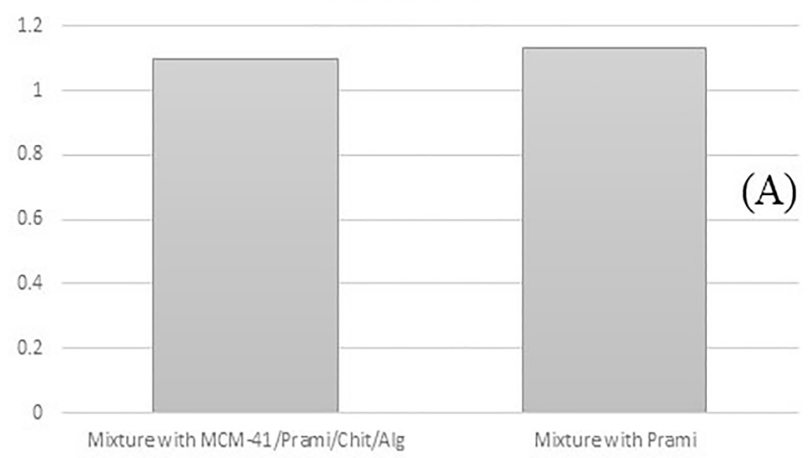

used for calculation of Hausner ratio (HR) and Carr's index (CI) (Figure 6).

No significant differences in HR were observed between mixtures, containing MCM-41 based systems and those containing pure pramipexole. CI of mixture with coated pramipexole loaded particle was influenced. Both parameters showed good compressibility and flowability for the powder mixtures. In accordance with good flowability and compressibility properties of the mixtures, preparation of tablets with nanoparticles was achieved by direct compaction method. Standard test for friability, crushing strength and disintegration time were used for tablet characterization (Table 2). Complete disintegration of the tablets occurred within 15 min and friability was less than $1 \%$. Thus, for both

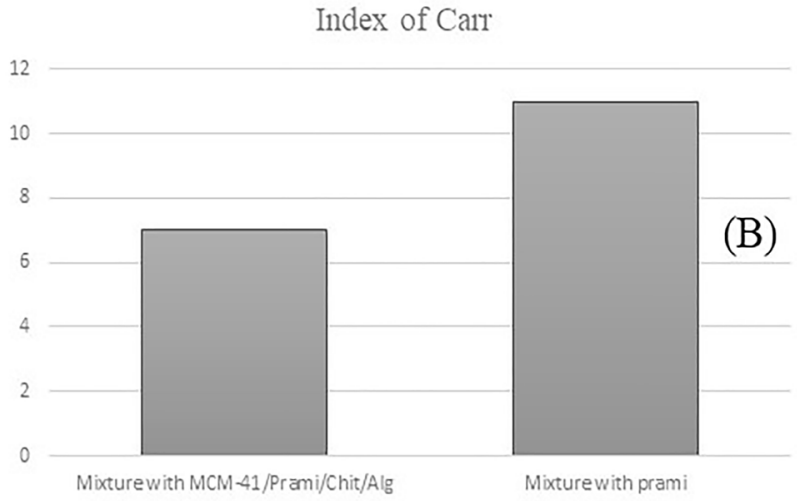

Figure 6: Hausner ratio $(A)$ and Carr's index $(B)$ of powder mixtures containing double coated pramipexole loaded MCM-41 and pure pramipexole.
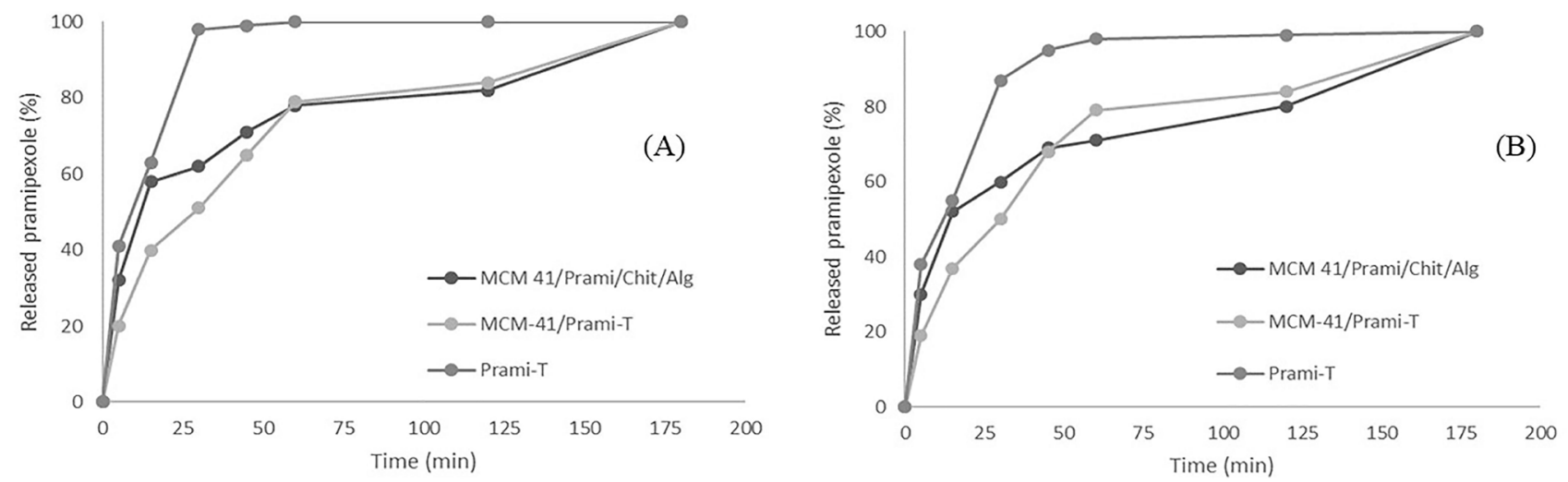

Figure 7: Release profiles of pramipexole from coated MCM-41 nanoparticles, tablets containing these nanoparticles and tablets containing pure pramipexole in $\mathrm{pH} 1.2(\mathrm{~A})$ and $\mathrm{pH} 6.8(\mathrm{~B})$.

parameters the requirements of Eur. Ph. were covered.

The crushing strength about $80 \mathrm{~N}$ was enough to ensure

tablet integrity during following technology stages.
Buffers with $\mathrm{pH}$ values 1.2 and 6.8 were used for dissolution tests. The release profiles from coated nanoparticles and tablets containing coated nanoparticles showed the achievement of slightly pronounced reduction of the initial release comparing 


\begin{tabular}{|c|c|c|c|c|}
\hline & $\begin{array}{c}\text { Average } \\
\text { mass }\end{array}$ & Disintegration & Friability & $\begin{array}{l}\text { Crushing } \\
\text { strength }\end{array}$ \\
\hline MCM -41/Prami-T & $148 \pm 3$ & Passed & $0.3 \%$ & $78 \mathrm{~N}$ \\
\hline Prami-T & $150 \pm 2$ & Passed & $0.1 \%$ & $83 \mathrm{~N}$ \\
\hline
\end{tabular}

to the tablets containing pure pramipexole (Figure 7). As seen, there is tendency for lower burst effect in the first $60 \mathrm{~min}$ for tablet formulations containing nanoparticles.

Reduced initial burst release compared to uncoated particles (Figure 5) was observed for all preparations. Alginate layer prevented release of pramipexole at $\mathrm{pH} 1.2$ and the contact of medium with chitosan layer. The $\mathrm{pKa}$ of guluronic and mannuronic acid residues of alginate are 3.65 and 3.38 respectively and alginate will shrink in a low $\mathrm{pH}$ medium allowing the dissolution of pramipexole. ${ }^{30}$ But in low $\mathrm{pH}$ medium, repelling of protonated amino group of chitosan may caused water sorption, and swelling that hamper the drug diffusion outside the pores. Therefore, a relatively swelled inner layer of chitosan in the gastric juice yields a relatively slow release rate from double coated silica particles. When $\mathrm{pH}$ is 6.8 an increase in the swelling of sodium alginate and to a reduction in the release of pramipexole, which diffuses through the polymer chains of chitosan. The pKa value of chitosan is 6.3 and at $\mathrm{pH} 6.8$ increased hydrophobic interaction are observed between polymer chains resulted in dehydration of them and induced a remarkable constriction. Initial burst release effect showed serious reduction at double polymer covered particles at $\mathrm{pH} 1.2$ and 6.8. On the other hand, interaction between amino groups of chitosan positively charged and negatively charged carboxyl groups of alginate could extra hindered drug release. However, tablets containing pure pramipexole practically fully released the drug within $25 \mathrm{~min}$. In this case the reduction of burst effect is due to the effect of tablet formulation and relatively long disintegration time of the tablets $(13 \mathrm{~min})$. Based on our results we conclude that formulation of MCM-41/Prami/Chit/ Alg particles into tablets influenced drug release only in first stages of dissolution process, avoiding or reducing the initial burst effect, minimize a high release rate over a short period, close to or above the toxic level.
Complete release from all samples was reached within 180 min at both $\mathrm{pH}$ media. Practically initial burst effect was not occurred.

\section{CONCLUSION}

Pramipexole was successfullyloaded on mesoporous silica MCM-41 carrier with high loading efficiency. Physicochemical characterization of initial, pramipexole-loaded and double-coated MCM-41 particles was made by DLS method, TEM and FTIR measurements.

The double polymer covering of the pramipexole loaded MCM-41 nanoparticles modified the release process. Due to the combination of chitosan and alginate the relese from pores of silica particles showed significant reduction in the initial burst effect at both $\mathrm{pH}$ values. The resulted pramipexole loaded post-coated MCM-41 nanoparticles were successfully formulated in tablets by direct compaction method. In vitro release studies showed that tablets prepared with double polymer covered silica particles influenced first stages of drug release.

\section{ACKNOWLEDGEMENT}

This work was supported by the Bulgarian Ministry of Education and Science under the National Program for Research "Young Scientists and Postdoctoral Students"

\section{CONFLICT OF INTEREST}

The authors declare that there is no conflict of interest.

\section{ABBREVIATIONS}

MCM-41: Mesoporous silica material - 41; DLS: Dynamic light scattering; TEM: Transmission electron microscopy; FTIR: Fourier-transform infrared spectroscopy; PD: Parkinson's disease; Prami: Pramipexole; Chit: Chitosan; Alg: Alginate; HPMC: Hydroxypropyl methylcellulose; PEG: Polyethylene Glycol; HR: Hausner ratio; CI: Carr's index; Pram-T: Pramipexole tablets; Eu.Ph.: European pharmacopeia. 


\section{REFERENCES}

1. Vallet-Regi M, Ramila A, Real DRP, Pérez-Pariente J. A new property of MCM-41: Drug delivery system. Chem Mater. 2001;13(2):308-11.

2. Vallet-Regí $M$, Balas $F$, Arcos D. Mesoporous materials for drug delivery. Angew Chem Int Ed. 2007;46(40):7548-58.

3. Hartmann M. Ordered mesoporous materials for bioadsorption and biocatalysis. Chem Mater. 2005;17(18):4577-593.

4. Huh S, Wiench JW, Yoo JC, Pruski M, Lin VY. Organic functionalization and morphology control of mesoporous silicas via a co-condensation synthesis method. Chem Mater. 2003;15(22):4247-56.

5. Trewyn BG, Whitman CM, Lin VY. Morphological control of room-temperature ionic liquid templated mesoporous silica nanoparticles for controlled release of antibacterial agents. Nano Lett. 2004;4(11):2139-43.

6. Suzuki K, Ikari K, Imai H. Synthesis of silica nanoparticles having a wellordered mesostructure using a double surfactant system. J Am Chem Soc. 2004;126(2):462-3.

7. Ying JY. Design and synthesis of nanostructured catalysts. Chem Eng Sci. 2006;61(5):1540-8.

8. Ying JY, Mehnert CP, Wong MS. Synthesis and applications of supramoleculartemplated mesoporous materials. Angew Chem Int Ed. 1999;38(1-2):56-77.

9. Kresge CT, Leonowicz ME, Roth WJ, Vartuli JC, Beck JS. Ordered mesoporous molecular sieves synthesized by a liquid-crystal template mechanism. Nature. 1992;359(6397):710-12.

10. Salonen J, Laitinen L, Kaukonen AM, Tuura J, Björkqvist M, Heikkilä T, et al. Mesoporous silicon microparticles for oral drug delivery: Loading and release of five model drugs. J Control Release. 2005;108(2-3):362-74.

11. Li Y, Li N, Pan W, Yu Z, Yang L, Tang B. Hollow mesoporous silica nanoparticles with tunable structures for controlled drug delivery. ACS Appl Mater Interfaces. 2017;9(3):2123-9.

12. Kaneniwa N, Imagawa K, Ichikawa JI. The effect of particle size on the compaction properties and compaction mechanism of sulfadimethoxine and sulfaphenazole. Chem Pharm Bull.1988;36(7):2531-7.

13. Hersey JA, Cole ET, Rees JE. Powder consolidation during compaction. In the Proceedings of the first international conference on the compaction and consolidation of particulate matter. Powder Technol Publ Ser. 1974;4:165-72.

14. Roberts RJ, Rowe RC. The effect of the relationship between punch velocity and particle size on the compaction behavior of materials with varying deformation mechanisms. J Pharm Pharmacol. 1986;38(8):567-71.

15. Bremmell KE, Tan A, Martin A, Prestidge CA. Tableting lipid-based formulations for oral drug delivery: A case study with silica nanoparticle-lipidmannitol hybrid microparticles. J Pharm Sci. 2013;102(2):684-93.
16. Konta B, Frank W. The treatment of Parkinson's disease with dopamine agonists. GMS Health Technol Assess. 2008;4(5):1-11.

17. Pellicano C, Benincasa D, Fanciulli A, Latino P, Giovannelli M, Pontieri FE. The impact of extended release dopamine agonists on prescribing patterns for therapy of early Parkinson's disease: An observational study. Eur $\mathrm{J}$ Med Res. 2013;18(1):60-5

18. Chauhan MJ, Patel SA. Formulation Optimization of pramipexole dihydrochloride prolong release tablets by implementation of design of experiment tool. Inv Imp Pharm Tech. 2013;613:1-12.

19. Wong TW, Chan LW, Kho SB, Heng PS. Design of controlled release solid dosage forms of alginate and chitosan using microwave. J Control Release. 2002;84(3):99-114.

20. Venkatesan J, Kim SK. Chitosan composites for bone tissue engineering: An overview. Mar Drugs. 2010;8(8):2252-66.

21. Peppas NA, Hilt JZ, Ali K, Robert L. Hydrogels in biology and medicine: From molecular principles to bionanotechnology. Adv Mat. 2006;18(11):1345-60.

22. Sachan NK, Pushkar S, Jha A, Bhattcharya A. Sodium alginate: The wonder polymer for controlled drug delivery. J Pharm Res. 2009;2(8):1191-9.

23. Stevens $M$, Qanadilo $H$, Langer $R$, Shastri V. A rapid-curing alginate gel system: Utility in periosteum-derived cartilage tissue engineering. Biomaterials. 2004;25(5):887-94.

24. Srinubabu G, Jaganbabu K, Sudharani B, Venugopal K, Girizasankar G, Rao JS. Development and validation of a LC method for the determination of pramipexole using an experimental design. Chromatographia. 2006;64(12):95-100.

25. Venkateswarlu K, Thakur H, Babu TB. Fabrication of Extended Release Tablets of Pramipexole: In-vitro Studies. Pharm Methods. 2017;8(2):115-20.

26. Romero AA, Alba MD, Zhou W, Klinowski J. Synthesis and characterization of the mesoporous silicate molecular sieve MCM-48. J Phys Chem B. 1997;01(27):5294-300

27. Takahashi R, Sato S, Sodesawa T, Kawakita M, Ogura K. High surface-area silica with controlled pore size prepared from nanocomposite of silica and citric acid. J Phys Chem B. 2000;104(51):12184-91.

28. Sartori C, Finch DS, Ralph B, Gilding K. Determination of the cation content of alginate thin films by FTIR spectroscopy. Polymer. 1997;38(1):43-51.

29. Li T, Shi XW, Du YM, Tang YF. Quaternized chitosan/alginate nanoparticles for protein delivery. J Biomed Mater Res A. 2007;83(2):383-90.

30. Mukhopadhyay P, Sarkar K, Soam S, Kundu PP. Formulation of pHresponsive carboxymethyl chitosan and alginate beads for the oral delivery of insulin. J Appl Polym Sci. 2013;129(2):835-45.

\section{PICTORIAL ABSTRACT}
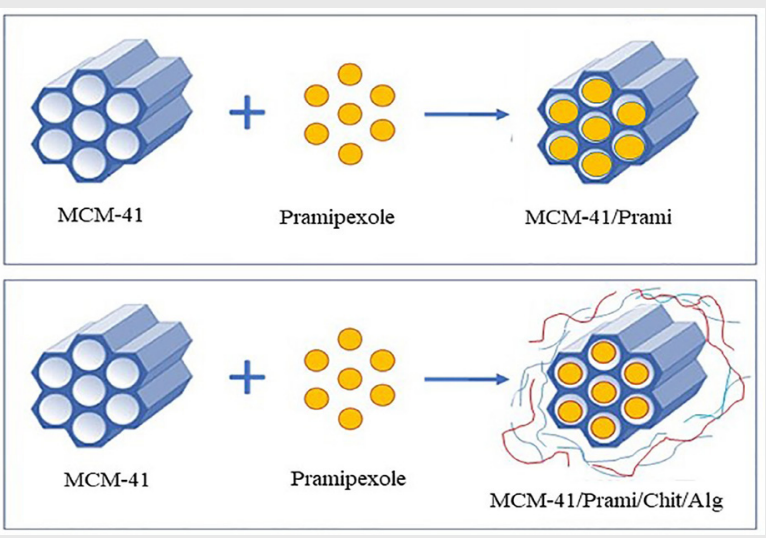

\section{SUMMARY}

MCM-41 particles were used and successfully loaded with active substance pramipexole. Drug loading method was modified by our team solvent impregnation method and led to sufficient efficacy of pramipexole loading. Characterization of resulted systems was made by DLS method, TEM and FTIR measurements. Modification of drug release was achieved by further formation of double chitosan/alginate coating of coated particles and was characterized. Release profiles from uncoated and chitosan/alginate-coated particles in different $\mathrm{pH}$ media showed significant differences in the dissolution rate. In order to develop final pharmaceutical product, the mesoporous silica particles loaded with pramipexole were formulated in the applicable solid dosage forms - tablets. Test for friability, crushing strength and disintegration time were used for tablet characterization. In vitro release studies of tablets prepared with coated particles showed influenced drug release only in first stages of dissolution process, avoiding or reducing the initial burst effect minimize a high release rate over a short period, close to or above the toxic level. 


\section{About Authors}

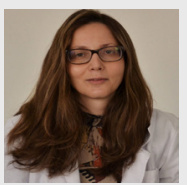

Christina Voycheva has earned Ph.D and is currently working as Assistant Professor at Medical University of Sofia, Faculty of Pharmacy, Department of Pharmaceutical Technology and Biopharmacy.

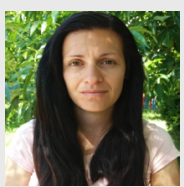

Teodora Popova has earned Ph.D and is currently working as Assistant Professor at Medical University of Sofia, Faculty of Pharmacy, Department of Pharmaceutical Technology and Biopharmacy.

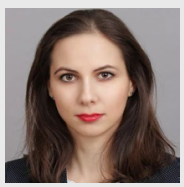

Marta Slavkova has earned Ph.D and is currently working as Assistant Professor at Medical University of Sofia, Faculty of Pharmacy, Department of Pharmaceutical Technology and Biopharmacy.

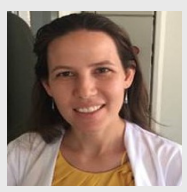

Diana Tzankova has earned Ph.D and is currently working as Assistant Professor at Medical University of Sofia, Faculty of Pharmacy, Department of Pharmaceutical Chemistry.

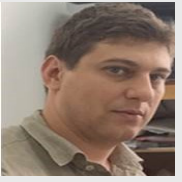

Borislav Tzankov has earned Ph.D and is currently working as Associate Professor at Medical University of Sofia, Faculty of Pharmacy.

Cite this article: Voycheva C, Popova T, Slavkova M, Tzankova D, Tzankov B. Formulation of Tablets Containing Mesoporous Silica Nanoparticles Loaded with Pramipexole. Indian J of Pharmaceutical Education and Research. $2021 ; 55(3): 692-700$. 